\section{Alberto Giannini \\ Visiting policies and family presence in ICU: a matter for legislation?}

Accepted: 17 September 2012

Published online: 28 September 2012

(C) Springer-Verlag Berlin Heidelberg and ESICM 2012

Dear Editor,

The Italian Senate Committee on Health recently started examining a bill on the subject of visiting policies and family presence in ICU [1].

In Italy, healthcare is largely in the hands of the regional governments, though parliament retains the power to dictate general policy. The bill in question-a brief document of four articles-stipulates that the introduction of the "open" ICU model [2] constitutes a primary objective of the national health plan; it therefore mandates the Health Ministry and the regional governments to establish norms on five key points. Firstly, recognizing a specific patient right, it states that daily visiting time should be at least $12 \mathrm{~h}$ in adult ICUs and without restrictions in neonatal and pediatric ICUs. Secondly, it requires that suitably qualified personnel should be available in ICU to provide appropriate psychological support to the patient and family members. Thirdly, it stipulates the creation of specific training paths for ICU doctors and nurses, with particular attention to communication skills (recognized as an area of professional competency). Fourthly, it sets out that hospital construction plans should be drawn up in such a way as to facilitate the creation of the "open" ICU model of care (incorporating, for instance, areas suitably equipped for family members). Finally, it links National Health Service supplementary funding for the regional governments to implementation of the law, ensuring that to some extent "open" ICU becomes a requirement for a hospital's accreditation in the Italian National Health Service.

That such a bill exists undoubtedly indicates the interest of the whole of society in these issues, which can today no longer be considered an exclusive prerogative of physicians and nurses. However, do we actually need a law on visiting in ICU? Is it right to have legislation on every aspect of medical practice, or should we consider it an unwarranted intrusion? In principle, I believe it is neither useful nor appropriate that legislation should dictate every detail of every aspect of medical activity and hospital life, rather than confining itself to addressing the definition of health policy.

We must, however, acknowledge that in some areas parliamentary intervention can be decisive in "making the leap" to achieve higher quality and standardize practice. An example is the recent law passed in Italy governing palliative treatment and pain management [3], stipulating that particular attention be paid to these aspects from both the clinical and the organizational point of view.

Italian ICUs today still apply particularly restrictive visiting policies: current daily visiting time is around $2 \mathrm{~h}$ with $2 \%$ of ICUs allowing $24 \mathrm{~h}$ visiting, while in $1.4 \%$ of units no visiting whatsoever is allowed [4]. Moreover, no waiting room is provided by $25 \%$ of ICUs [5].

Neither the European nor the Italian Societies of Intensive Care Medicine have yet made recommendations about this. However, in my view, they should issue a strong statement of position, acknowledging clearly and unequivocally the importance of these matters to quality of care in ICU, and urging the liberalization of visiting policies. A statement of this kind could reduce the need for parliament to become involved in excessive detail. As things stand, however, a simple "policy" law like the one under consideration could be a useful tool in fostering the necessary cultural and organizational change.

\section{References}

1. Disegno di Legge n. 3248 “Disposizioni in materia di Reparti di Terapia Intensiva aperta". XVI Legislatura, Senato della Repubblica (http://www. senato.it/japp/bgt/showdoc/frame. jsp?tipodoc $=$ Ddlpres\&leg $=16 \& \mathrm{id}=$ 00660437\&part=doc_dc-articolato_ ddl\&parse=no). Accessed 31 Aug 2012

2. Giannini A (2010) The "open" ICU: not just a question of time. Minerva Anestesiol 76:89-90

3. Legge 15 Marzo 2010, n. 38 "Disposizioni per garantire l'accesso alle cure palliative e alla terapia del dolore". Gazzetta Ufficiale n. 65, 19.3.2010 (http://www.parlamento. it/parlam/leggi/100381.htm). Accessed 31 Aug 2012

4. Giannini A, Marchesi T, Miccinesi G (2011) "Andante moderato": signs of change in visiting policies for Italian ICUs. Intensive Care Med 37:1890

5. Giannini A, Miccinesi G, Leoncino S (2008) Visiting policies in Italian intensive care units: a nationwide survey. Intensive Care Med 34:1256-1262

\section{A. Giannini (}

Pediatric Intensive Care Unit,

Fondazione IRCCS Ca' Granda, Ospedale Maggiore Policlinico,

Via della Commenda 9,

20122 Milan, Italy

e-mail: a.giannini@policlinico.mi.it

Tel.: +39-02-55032242

Fax: +39-02-55032817 